\title{
Showrooms as a Window to Science Based Innovation
}

\author{
Michael Boronowsky ${ }^{1}$, Tanja Woronowicz ${ }^{2}$, Peter Hoffmann ${ }^{3}$, Sangin Boboev ${ }^{4}$, \\ ${ }^{1,2}$ University of Bremen, Germany, ${ }^{3}$ FOM University of Applied Sciences for Economics and Management, \\ Germany, ${ }^{4}$ Technological University of Tajikistan, Tajikistan
}

\begin{abstract}
Scientific results benefit from more tangible stakeholder communication. Showrooms are a tool to transform abstract scientific concepts into solution-oriented and less complex demonstrators. The basic idea of a showroom implies a smart expo and meeting place to demonstrate the latest technological developments in a comprehensive and interactive manner and to stimulate transfer of scientific results to practice. Presentation of new technologies can be an eye opener of what can already be done today. But it is just more than this as it can put discussion with interested stakeholders to a new level - allowing to think beyond this - paving the ground for innovation. This way a showroom stimulates very substantial discussion about future ideas with real involvement of industry and society. Involving the public via a showroom environment is also helpful for the diffusion of new ideas, leading to potential faster market take-up, when new solutions are put into reality. Furthermore the interaction with the public is a stimulus also for the scientist, raising a much better understanding about current and future needs.

Capability is understood as a measure of the ability of an entity (organization, person, system) to achieve its objectives in relation to its overall mission professional science communication is part of the capability of, e.g., a university. Innovation capability in this sense refers to the ability of a set of regional stakeholders from academia, political authorities, public administrations and industry to innovate in synergy for economic and societal development - showrooms are an important tool to achieve this.
\end{abstract}

Keywords - science industry interface; innovation capability; science communication; showroom.

\section{INTRODUCTION}

Stakeholder outreach is a key strategic pursuit in building the reputation of any transfer-oriented research institution. The European INTERREG project BONITA created the Innovation Capability Maturity Model innoSPICE® [2] conformant to ISO/IEC 15504. This model can be used to improve the capability on innovation and transfer activities of public research organizations, incubators, technology parks and public agencies by successfully transferring research outcomes towards economic added value. innoSPICE $®$ employs a process reference framework as a foundation for managing and developing the innovation capabilities of an organization. Based on the best current practices in fields such as communication, knowledge management, project management, social networking, human resources/ organizational development and commercialization of research results, the Transfer Model will guide the assessment and improvement of processes for managing and developing transfer capabilities.
This paper will illustrate the dependency of innovation capability of a research organization regarding stakeholderoriented communication within an innovation ecosystem by introducing the showroom concept within several projects.

The research presented in this paper also illustrates the foundation for the extension of the showroom concept to Central Asia in the context of the eINTERASIA project founded by the European Commission. Furthermore, it enhances the realized showroom idea towards a virtual showroom network.

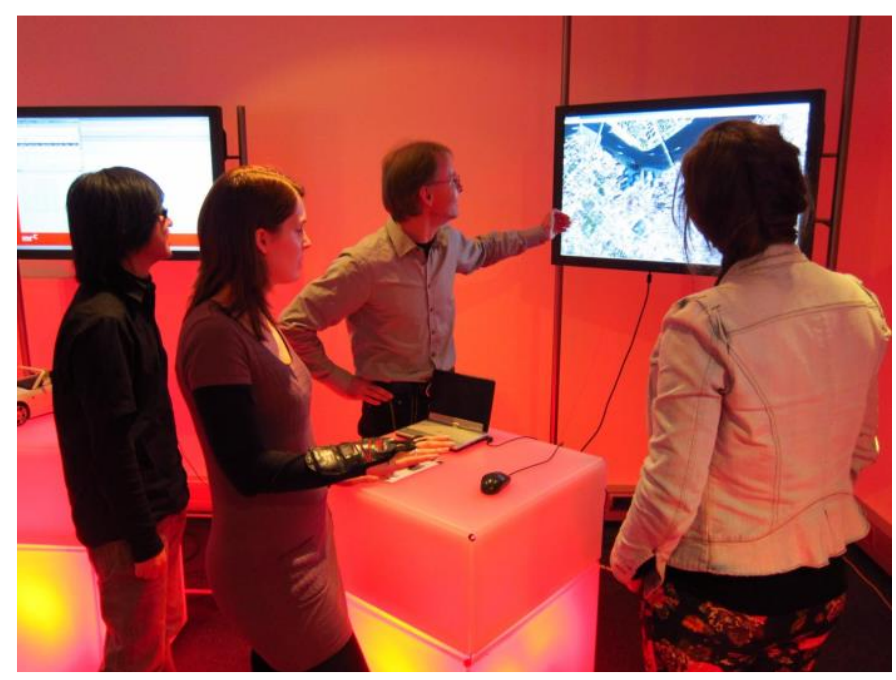

Fig. 1. Science communication needs more tangible forms of stakeholder interaction.

\section{SHOWROOMS}

\section{A. Background}

Professional exhibitions like "Hannover Fare" or "CeBIT" clearly demonstrate that showing the latest technologies is an attractor for a larger audience. There is still a hype also for a non-professional to see and feel new technologies. Even in the age of virtualization, reality has still its own attractiveness. In [1] it is concluded that "the job of communicating (technological) science might be to help non-scientists feel they are not excluded as opposed to always included; that they can join in if they want, rather than that there is a necessity to spend their lives engaging." The so-called showrooms that are operated by research organizations, are specialized demonstration spaces. They are acting as a communication interface between science and public. Putting research into a 
space for discussion with the public can close the gap to access university knowledge - like the elevator to the "ivory tower".

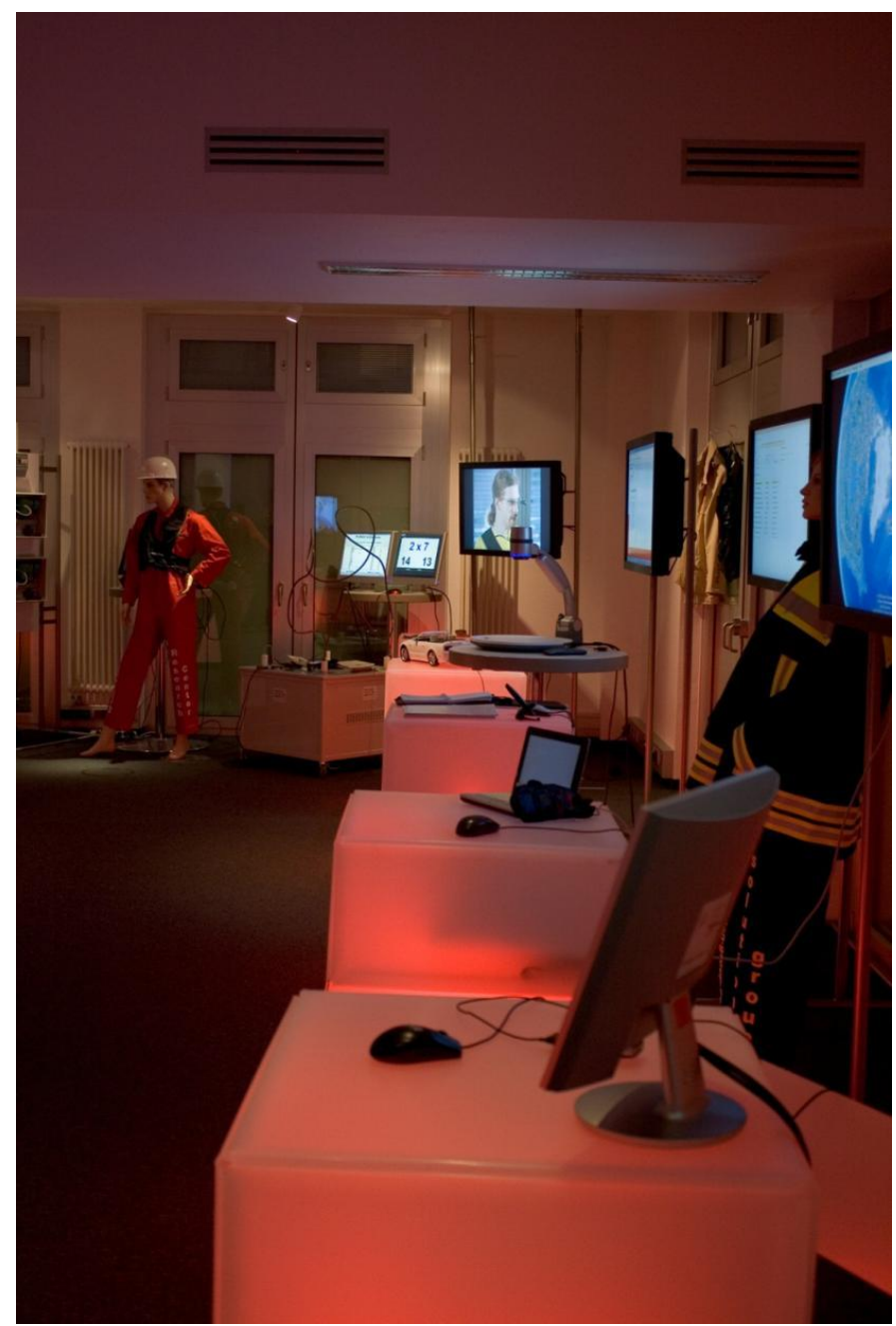

Fig. 2. Showroom for mobile technologies at the University of Bremen.

The concept of showrooms is drafted as a permanent exhibition allowing the complexity of specific research areas to be made understandable by the visitors. It presents new ideas and concepts that are feasible and that can be explored by the user. It is an important part of the innovation cycle: Talking of applications like cloud computing, intelligent logistics, advanced communication networks and other new scientific concepts, the showroom supports bi-directional transfer of technology - as well as push and pull from the recipient.

The idea of such an exhibition is to get closer to scientific results. University will professionalize marketing of own results by building exhibits for a showroom. This will raise attention of the public and will also help to justify the public investments in universities. It is also a new and unexpected way of communication and involvement of interested stakeholders. Outcomes of latest research are put into a practical context and new concepts are brought to the interest of the visitors. This way interested visitors will get in touch with technologies that are not known by a wider public. It will stimulate exchange of ideas between research and public, stimulate identification of new application areas. In addition to technically interested laypeople, the target group might be anyone else who potentially gains genuine benefit from the technologies on show [6].

\section{B. BONITA Showrooms}

For the Center of Computing and Communication Technologies (TZI), the showroom has become an important element in the technology transfer process. The transformation of elaborated scientific results into tangible exhibits opens a new public viewport to science. But it is also a way to interact with the local actors of the innovation cycle:

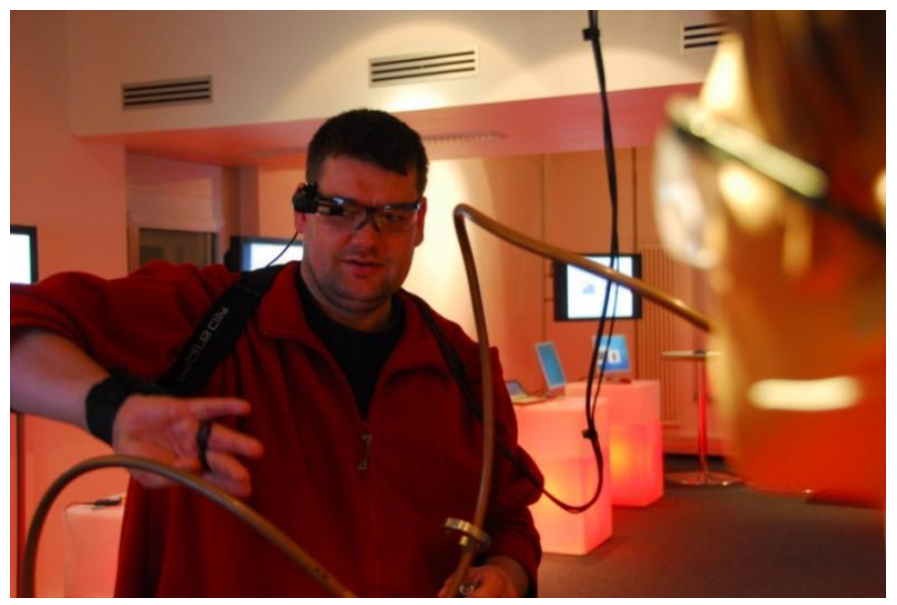

Fig. 3. Touching and trying latest technologies.

a. A market place for the exchange of ideas between different stakeholders within the innovation cycle, like the end user, creator of new solutions, scientists or politicians etc. It will help to increase the level of knowledge about the opportunities of new technologies, and also will help to take concerns into account in an early stage;

b. An opportunity to promote technologies - to invite people to try new solutions by themselves; to see high tech in new applications. The main aspect it to bring people in touch with the latest developments and to make them understand the state of the art.

One research area at TZI deals with computers that are worn like clothes - the so-called wearables. This technology actually has become more visible due to the development of "google glasses". For several years the paradigm of this development has only be known within the research community. The innovative character of this concept is not obvious if you just look at the individual components. Just seeing pictures or the devices without a concrete function does not reveal deeper principles. Functional prototypes are a much better way to learn about the aspects of the technologies, as it is a strong and practical illustration. Starting a dialog based on this understanding with potential users motivates very substantial discussions about the advantages and disadvantages of new solutions based on this technology, e.g., a worker responsible for maintenance of technical devices can reflect on the use of wearables in his application domain. New insights can be not only specific concerns but also motivating feedback for even more useful applications. Putting these technologies under 
discussion in a showroom environment allows one to be more targeted in explaining this paradigm with more attention of the listener because of his involvement. The experience made in the showroom at University of Bremen is underlining this observation.

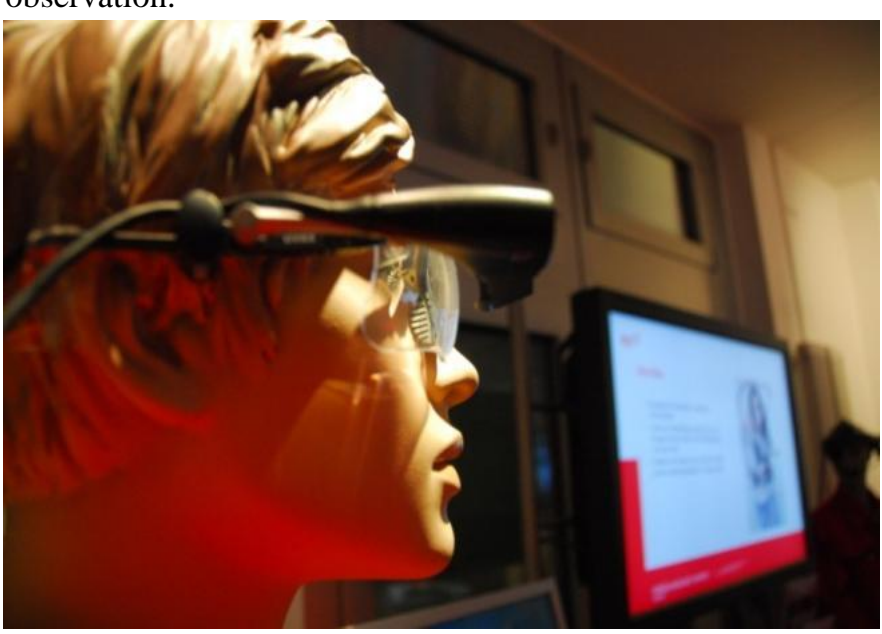

Fig. 4. Testing Head Mounted Displays to make public better understand research results in the area of wearable computing.

Connecting new technologies to real world problems and presenting them in a showroom structure oriented to solutions can increase the reputation of a research organization and also can impact the regional innovation system. As a logical consequence, people or companies who are interested in this topic, come to the region because of the facilities bundled there. The exchange with the experts that are present during a showroom visit can be an important step for the diffusion of new ideas and can have influence on the take-up of technologies in real world environments - leading to innovations.

The BONITA network showrooms are based on Bremen experience to present science-based applications to different stakeholder groups. All BONITA showrooms share as a common element the principle of being the regional entry point for the targeted exchange of innovation chain stakeholders from academia and industry. Here those scientists are invited to demonstrate their latest technology and to communicate on the regional level and also on the international level that is provided by the project consortium. Apart from the exchange of prototypes between the partners, one additional element is the exchange of promotional videos used to show specific technologies and solutions in an applied context. The international collaboration is an attractor also for the visitors of the showroom, as knowledge about innovative ideas is based on a wider international network. Besides, it is also increasing the exchange between the individual showroom partners, and this can lead to a better alignment in specific research areas.

The BONITA project introduced an interactive screen concept - the so called multi-touch interfaces - as a common showroom element. These devices allow breaking up with traditional forms of presentations, such as slides projected on the wall. Due to a high level of interaction the audience can be involved with a high level of interaction. Information is made available in an intuitive way and can combine any multi-media based content.

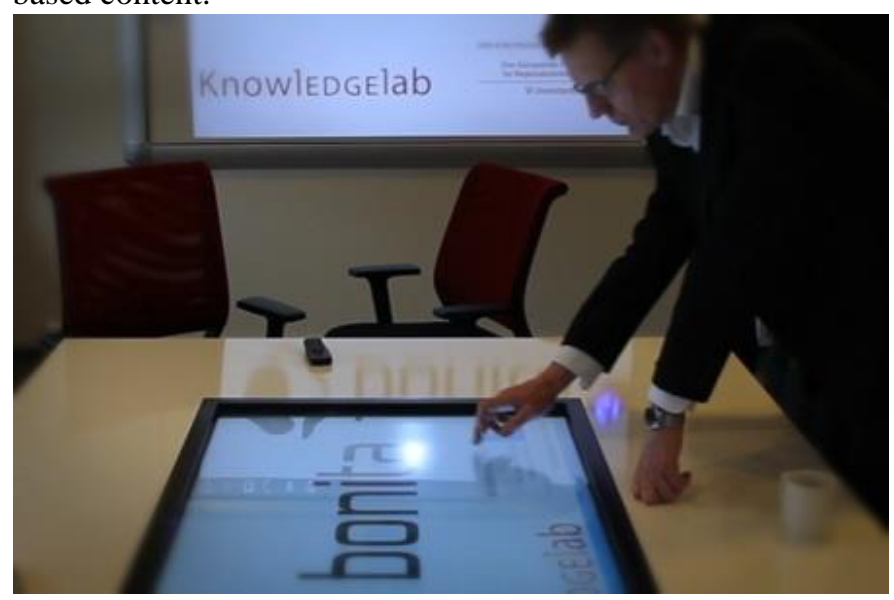

Fig. 5. Multi-touch table in the showroom at South Denmark University.

During the BONITA project, showrooms for mobile IT applications were established in Riga, Vilnius, Tampere, Lulea, Odense and Bremen. The different regional showrooms and the virtual exhibition provide a unique and excellent opportunity to get attention and to involve SMEs and policy makers as they link the project aims to a concrete demonstration scenario. The outreach via the showrooms towards private companies is not only for dissemination, but also for generating and stimulating economic added value to public funded research.

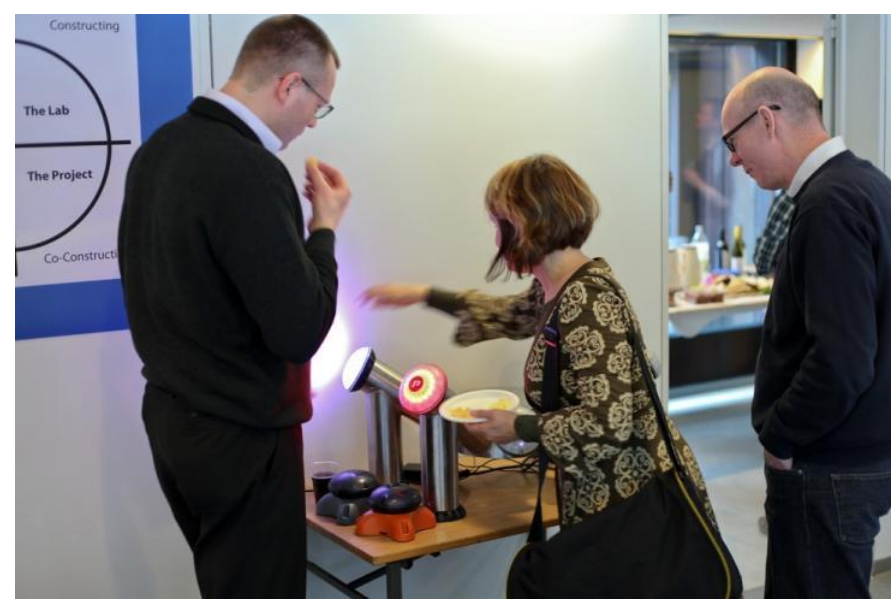

Fig. 6. Presenting research results as showroom demonstrator to the public.

\section{Virtual Showrooms}

In [6] the concept of virtual showrooms is introduced and discussed. A short summary of this discussion is presented in this section to add this level of showroom operation.

Expanding the showroom into virtuality is auspicious, since it allows different audiences to actively engage in enhancing the knowledge about the exhibits - both in the scientific and the commercial sense [6]. 


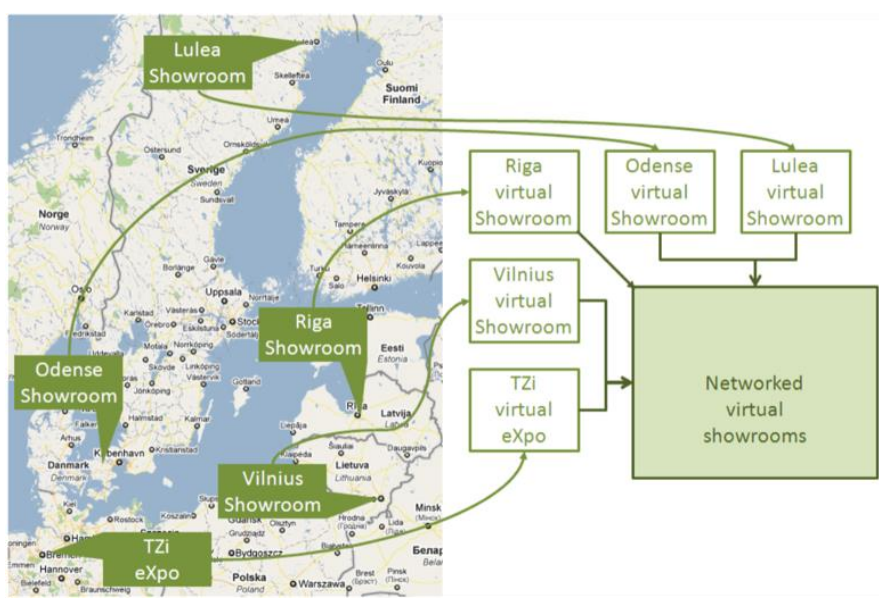

Fig. 7. From real showrooms to a network of virtual showrooms.

It is obvious that "the growth of the Internet offers unique opportunities for science to establish additional channels of communication with the public. Science topics and information will be there, but the question is, will the scientific community have a prominent role in disseminating it?" [3]. In [4] it is suggested that researchers need the capability to convert their results in "language and idiom". Information is easily distributed via the World Wide Web, but it has to be transferred into the language of the recipient. Thus, a virtual showroom should be able to present information on different levels, according to the target group. It can span the bow from lightweight video features to more text and image based representations up to deeper presentation of the research. "This offers the added value of a more holistic explanation of the theory and research behind the exhibits. Thereby, the public presentation of the institution itself benefits to a great extent, creating a positive impact on the transfer to and from possible industry partner" [6].

\section{The eINTERASIA Showrooms}

The network of BONITA showrooms is further evolving and based on its experiences, a new showroom is set up in the framework under the auspices of the FP7 Program of the European Union: A project consortium of nine partners from Europe and Central Asia led by Riga Technical University established in Dushanbe within the Technological University of Tajikistan - the eINTERASIA Showroom. The purpose of this new facility includes:

a. The demonstration, analysis and test/ applications of different IT solutions and EU research results supporting mainly the business process in the industrial sector of eLogistics;

b. The facilitated transformation of research findings and promotion of technology transfer by creating a new network for innovation \& technology transfer with local Central Asian SMEs, governmental organizations and academic institutions.

Currently, the eINTERASIA Showroom at the Technological University of Tajikistan is mainly used for academic purposes, where teachers, researchers, students demonstrate their scientific and innovation achievements to visitors and interested parties. In addition, within the showroom there is an ICT Study Group established under the title "Creators of a Knowledge Based Society" to further evolve the exchange of industrial ICT specialists, students and academic staff.

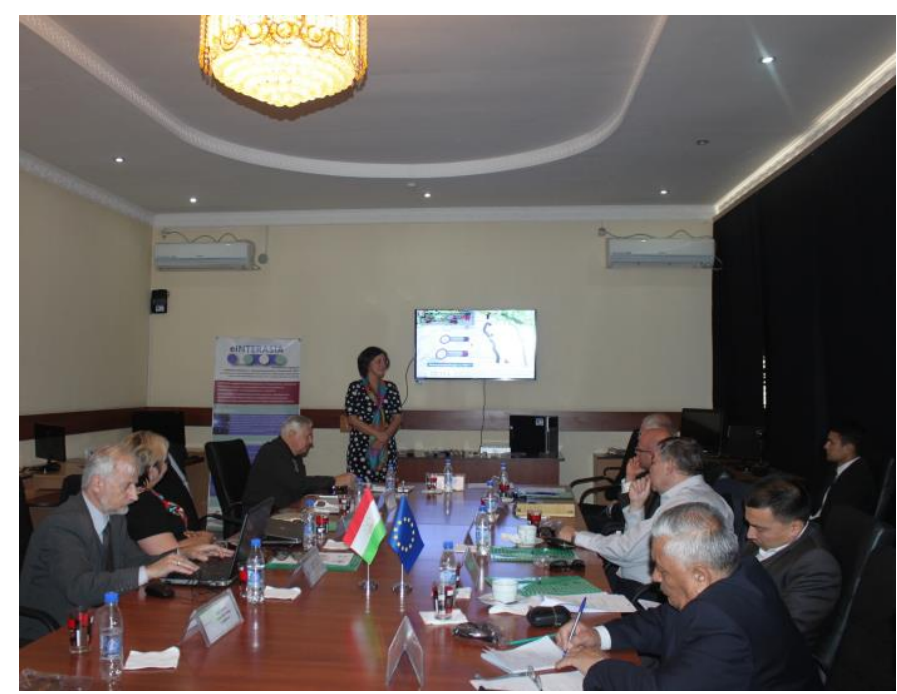

Fig. 8. eINTERASIA meeting related to the opening of the showroom in Dushanbe.

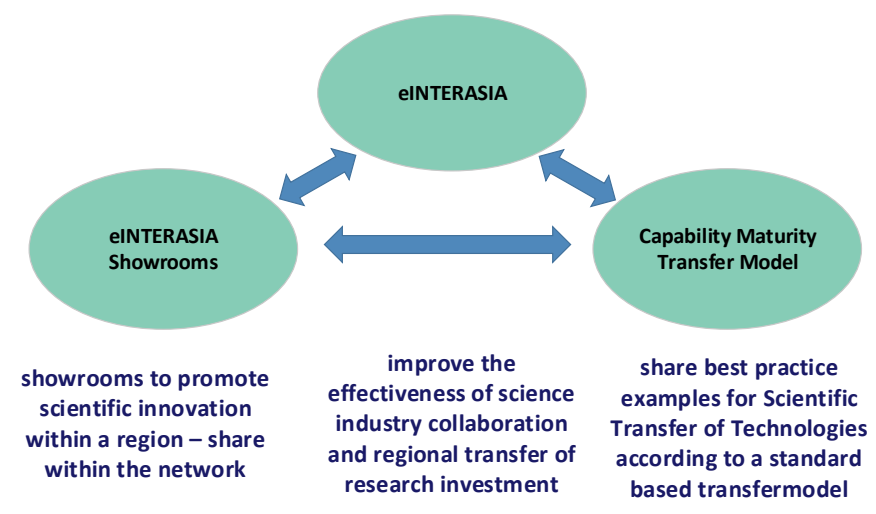

Fig. 9. Relation between eINTERASIA Showrooms and Capability Maturity in Knowledge and Technology Transfer.

\section{SHOWROOMS AS A TOOL FOR AN IMPROVED INNOVATION CAPABILITY}

The project consortium is working on the innovation ecosystem capability improvement, because at the beginning of running a showroom, generally the involved researchers and, if available, technology transfer managers are not yet fully or adequately prepared to perform their new implicit responsibilities of preparing economic impact by this infrastructure. The new established eINTERASIA showroom gave many insights to the project consortium how important innovation capability building is if you want to use existing infrastructure like showrooms effectively. Though cooperation and effective alliances of universities, public funded research organizations, science parks and knowledge intense industry take place in quite different ways, depending on traditions, 
resources and economic structures, they are always depending on active commitment and competencies of the involved actors within their organizational structures and its interfaces to the regional innovation ecosystem: "Differences in regional institutions and the interplay between them matter profoundly to competitive success because the innovation does not take place in an institutional vacuum. Rather it is determined by the configuration of businesses, finance, research, education, and more. All these institutions and organizations have a local expression. All organizations play an incredible important, yet subtle and multifaceted role in our local ecosystems. It is a twoway process. The better organizations understand their role and their role is understood - the better they can underpin the ecosystem; equally the stronger the ecosystem, the easier it is for organizations to grasp and seize their role in its division of labor" [5].

If capability is understood as measure of the ability of an entity (organization, person, system) to achieve its objectives in relation to its overall mission, then innovation capability in this sense refers to the ability of a set of regional stakeholders from academia, political authorities, public administration and industry to innovate in synergies for economic and societal development. The integration of the sometimes contradictory interest depends to a large extent on the capability of the organization staff to see each other's position and interests. To better utilize capacity of the regional innovation ecosystem, it is necessary to take into account the formal and informal cooperation mechanisms, perspectives from multiple protagonists and bidirectional relationships as well as the heterogeneity of the knowledge generation entities as a need for specific skills and competencies within defined interfaces. The ability to act reliably in cooperation environments is a crucial success factor to enhance the economic competitiveness. The established showrooms are one element within the approach of regional capability improvement to stimulate synergies through joint R\&D, knowledge transfer and innovation activities. Furthermore, they inspire a better-developed spirit of entrepreneurship and an enhanced understanding of the potential of the added value on professionalized knowledge transfer for all stakeholders.

As a result of incorporating ongoing technology transfer orientation in the performance of public funded research activities within a regional but networked showroom, these activities become more consistent across units and organizations within the innovation ecosystem. Now inputs for potential improvements might come from many sources: They can come from lessons learned in presenting a prototype in either the physical or the virtual showroom, from suggestions by visiting domain experts, or from the exchange of results in between the network of showrooms. It is critical for effective usage of a showroom to have the needed structures and a set of skills for transfer and cooperation activities instead of considering them to be just administrative - something less than real scientific work. The showroom hosting organization as well as the surrounding innovation ecosystem with political and industrial stakeholders should develop a common vision about the fundamental responsibilities of knowledge transfer from public funded research into the region: Therein the showroom is a tool within the regional innovation toolbox supporting transfer activities not only as to be about producing results, but as producing shared knowledge which produces results.

Once a showroom has been established, the next step could be for both the hosting research organization and the regional ecosystem to build their enhanced exchange activities that tie the capability for transfer and innovation to strategic objectives. The focus will be on incorporating a synergetic orientation in the performance of agreed interfaces and processes; it should become more consistent across regional organizations. The primary objective for the participating innovation ecosystems is to gain a competitive advantage by developing various competencies that must be combined to accomplish transfer activities as a defined added value: this innovation capability represents the critical pillars for further regional development.

\section{CONCLUSION}

Professional science communication is a relevant area for scientific organizations because of an increasing demand from society to understand the value of, e.g., investments in scientific infrastructures of research projects. On the other hand, professional stakeholder communication is an important element to build serious partnerships between science and society or industry. This also enables additional streams of private funding, e.g., for common innovation oriented science industry collaboration. This requires interest from universities to take an active part to communicate research results not only within scientific community. Addressing the non-scientific community requires often translating one's own results to make them more tangible and understandable also for non-experts. As this always comes along with additional work for a research organization, a clear strategic foundation within the organization is elementary. Showrooms are an instrument for professional scientific communication to various stakeholder groups. They can provide an environment one can find at bigger trade shows and fares, but organizations need to have the suitable capability to present results in this kind of setting. Selling science to science is very different than selling science to the public. Skills like communication and marketing are needed to transform and abstract scientific results to something attractive, possibly even entertaining. And for continuous operation, organizational processes are needed to ensure that exhibits are functional or updated, and that new research results are transferred to new showroom exhibits.

Experience has shown that showrooms can stimulate stakeholder interaction and that this infrastructure also attracts scientists to meet with their potential partners within the showroom facilities. They are a way to improve universities and research organizations' accessibility and contribute to the professionalization of communication within the science/industry and science/society interface. 


\section{REFERENCES}

[1] Priest, S.H., "Reinterpreting the audiences for media messages about science," Holliman, R., et al. (eds.) Investigating Science Communication in the Information Age: Implications for Public Engagement and Popular Media, Oxford: Oxford University Press, pp. 223-236, 2009.

[2] Besson, J., Woronowicz, T., Mitasiunas, A., Boronowsky, M., "Innovation, Knowledge- and Technology Transfer Process Capability Model - innoSPICE ${ }^{\mathrm{TM}}$," The Proc. of the 12th Int. Conf., SPICE 2012, Palma, Spain, May 29-31, 2012, Software Process Improvement and Capability Determination Communications in Computer and Information Science, vol. 290, pp. 75-84, 2012. http://dx.doi.org/10.1007/978-3-64230439-2 7

[3] Suleski, J., "Scientists are talking, but mostly to each other: a quantitative analysis of research represented in mass media" Public Understanding of Science, vol. 19, no. 1, pp. 115-125, March 31, 2009. http://dx.doi.org/10.1177/0963662508096776

[4] Kua, E., Reder, M. and Grossel, M.J., "Science in the News: A Study of Reporting Genomics," Public Understanding of Science, vol. 13, no. 3, pp. 309-322, 2004. http://dx.doi.org/10.1177/0963662504045539

[5] Anderson, B. and Hutton, W., Raising the potential of the Triple Helix, London, 2013. [Online]. Available: http://www.biginnovationcentre.com/ universities-and-innovation-centres

[6] Woronowicz T., Hoffmann P., Boronowsky, M., "Interseum - From Physical to Virtual Showrooms," In Advances in Multimedia and Network Information Systems Technologies. Advances in Soft Computing, vol. 80 pp. 3-13, 2010. http://dx.doi.org/10.1007/978-3-642-14989-4

Michael Boronowsky is a Managing Director of the Innovation Capability Unit at the Center for Computing and Communication Technologies, University of Bremen. In 1992, he finished his studies in electrical engineering at the University of Applied Science Aachen. Then he worked in a measurement device company as a Leading Development Engineer. He went back to the university and studied Computer Science in Nijmegen (Netherlands) and received a Master Degree in Computer Science in 1995. Since this time he has been working at the University of Bremen. In the beginning he was working in the area of Artificial Intelligence research. In 1999 he became responsible for coordinating the Wearable Computing research at the TZI. Dr. Boronowsky finished his Doctoral studies in 2001 and became a Managing Director of the Intelligent Systems Department. Since 2002 he has been a Managing Director of the TZI and has become a Manager of the Innovation Capability Unit this year. He coordinated the application of the IP-proposal "wearIT@work Empowering the Mobile Worker with Wearable Computing". He is an international expert in the field of knowledge and technology transfer and representative of the European Baltic Sea Region INTERREG 4B project BONITA.

E-mail: mb@tzi.de
Tanja Woronowicz is the Head of Development at the Innovation Capability Unit of TZI - University of Bremen. After 5 years in industry (sales management, HRD), she came back to the university in 2007, working as an IT Security Assessor (ISO 27001) and European Project Manager. Tanja holds a Master Degree in Geographical Information Systems from Paris-Lodron University in Salzburg, Austria. Tanja has been a Project Manager of the Baltic Sea Region project BONITA that has developed the Innovation, Knowledge and Technology Transfer capability model innoSPICE and is a co-author of innoSPICE standard based model. Tanja is also a Lecturer at Bremen University of Applied Sciences. She was a Manager and a Trainer in two projects to improve the knowledge and technology transfer capacity within the Lithuanian innovation system based on innoSPICE. She performed several assessments based on innoSPICE as a Lead Assessor at universities, research organizations, science parks in several European Countries.

E-mail: worono@tzi.de

Peter Hoffmann has a Diploma in Safety Engineering with the focus on Fire and Explosion Protection from the Bergische Universität Wuppertal. At the Zentrum für Graphische Datenverarbeitung (ZGDV) in Darmstadt he started his career as a Software Developer and Researcher. In 2002 he changed to the Institute for Multimedia and Interactive Systems (IMIS) at the University of Luebeck, where he was a Lecturer and a Researcher in Multimedia and Hypermedia Systems. In 2010 he received his Doctoral Degree for the research in Narrative Realities. From 2008 to 2013 he was the Managing Director of the concerted activity Mobile Solutions at the TZI, the University of Bremen with the focus on Ambient Assisted Protection and the research of Dynamic Hypermedia for the use of E-Learning and exhibitions. Since 2013 Dr. Peter Hoffmann has been a University Lecturer at the FOM University of Applied Sciences for Economics and Management.

E-mail : info@form-i.de

Sangin Boboev graduated from the Faculty of Foreign Languages of Tajik State Pedagogical University named after S. Aini (TSPU) in 2006. He is a Doctoral Student at Tajik National University, the Department of History of Language and Comparative Typology. He started his teaching career at the Chair of English Philology and Comparative Typology of TSPU. Since 2008 he has been working as a Lecturer at the Chair of Foreign Languages and European Model of Education, the Technological University of Tajikistan. Due to his strong interest in international cooperation, he was appointed the Head of the Office of International Relations at the Technological University of Tajikistan in January 2013.

E-mail : sanginboboev@gmail.com 